\title{
Dispositional Predispositions of Depression, Life Satisfaction, and Life Meaning among Chinese College Students
}

Xiao Dong Yue*, Chau Kiu Jacky Cheung, Neelam Arjan Hiranandani and Jiang Feng

Department of Applied Social Studies, City University of Hong Kong, 81 Chee Avenue. Kowloon Tong Hong Kong, SAR China

\begin{abstract}
Non-depression (i.e., the reverse of depression), life satisfaction, and life meaning are conceptually three different aspects of well-being. Their similarities and dissimilarities in relation to personality traits are an uncharted concern. For this concern, this study analyzes data collected from 6,210 Chinese students attending 52 colleges in Mainland China, Taiwan, Hong Kong, or Macau. Results show that on all the three well-being factors, neuroticism had negative effects, and extraversion, conscientiousness, and openness had positive effects. However, non-depression did not have significant effects on life satisfaction and life meaning. By contrast, personality traits still had effects on life meaning, after controlling for nondepression. Results unfold similarities and dissimilarities among the three well-being factors.
\end{abstract}

Publication History:

Received: November 24, 2017

Accepted: February 20, 2018

Published: February 22, 2018

\section{Keywords:}

Life meaning, Big five, Personality trait, Life satisfaction, Depression

\section{Introduction}

Life meaning is integral to existentialist well-being [1,2], whereas depression in a non-clinical sense and life satisfaction are common concerns for the hedonist well-being. Accordingly, hedonist wellbeing favors pleasure seeking and pain avoidance according to the person's desire, whereas existentialist well-being emphasizes the person's free will and self-determination to fulfill life [3,4]. As both hedonist well-being and existentialist well-being are reasonable ideals, non-depression, life satisfaction, and life meaning are worthy goals for investigation and pursuit $[5,6]$. In this connection, the person's personality in terms of the big-five traits of neuroticism, extraversion, conscientiousness, openness, and agreeableness provides a clue. Such personality traits have appeared to predispose depression and impede life satisfaction and life meaning [7-9]. Therefore, this paper aims to investigate the differential influences of personality traits among depression, life satisfaction, and life meaning.

Personality commonly consists of the big five traits of neuroticism, extraversion, conscientious, openness, and agreeableness (Classic studies? [10]). These traits tend to be stable and relevant to one's whole life $[11,12]$. The big-five schema has the merits of empirical validity and conceptual transparency [13]. Neuroticism means feeling anxious [12]. Extraversion means outgoing. Conscientiousness means dependability. Openness means sophistication. Agreeableness means sympathy. These personality traits have demonstrated pervasive influences, such as on creativity and academic achievement $[14,15]$. Nevertheless, because agreeableness did not show adequate reliability and convergent validity in this study, the study precludes agreeableness.

Personality traits are likely to predispose non-depression, life satisfaction, and life meaning or well-being altogether principally according to set-point theory [16,17]. The theory posits that personality traits as well as other stable characteristics determine and constrain one's well-being to keep it at equilibrium, even after some occasional perturbation. As such, personality or temperament such as extraversion and neuroticism are particularly determinative, through the processes of event creation and reaction $[18,19]$. That is, extraversion is likely to predispose one to happy events and foster one's pleasurable reaction to the event [20]. Conversely, neuroticism is likely to distract one from happy events and arouse unpleasant reactions to events [20].

Neuroticism is particularly likely to predispose depression, according to spectrum theory [21]. The theory regards neuroticism, depression, and other pathological conditions as lying on a spectrum of different degrees of intensity and durability. In the spectrum, neuroticism represents a chronic and generic trait, and depression indicates an acute and intense state. Hence, depression is a specific manifestation of neuroticism. Alternatively speaking, neuroticism enhances sensitivity to adverse cues, thus leading to depression [21].

Apart from the theories, research has pervasively shown the predisposing effects of personality traits on depression, life satisfaction, and life meaning. Concerning depression, neuroticism has shown a positive effect $[8,22]$. Openness has also exhibited a positive effect on depression [11]. In contrast, extraversion has shown a negative effect on depression [22]. Conscientiousness has also displayed a negative effect on depression $[3,11]$. As regards life satisfaction, neuroticism has manifested a negative effect $[7,23]$. By contrast, extraversion and conscientiousness have sustained a positive effect on life satisfaction $[7,23]$. Openness also generated a positive effect on life satisfaction [24]. Regarding life meaning, conscientiousness, extraversion has indicated a positive effect [25]. In contrast, neuroticism has evolved a negative effect on life meaning [25].

\section{Non-depression Effects on Life Satisfaction and Life Meaning}

Depression in a non-clinical sense refers to feelings of frustration or other obstructions [26]. It operates affectively, cognitively, somatically, and physiologically in a form of dysfunction or symptomatology. Depressive symptomology is common among youth to signal their vulnerability and immaturity $[27,28]$. It is a problem in youth in Mainland China and Taiwan as well $[29,30]$. The problem can culminate in cognitive, behavioral, physical, and relational disorders $[31,32]$. Depression is also problematic because of its chronicity in the youth [11]. As such, depression represents suffering psychological and biologically, and conversely, non-depression means the avoidance of pain, desired for hedonist well-being [33].

"Corresponding Author: Prof. Xiao Dong Yue, Department of Applied Social Studies, City University of Hong Kong, 81 Chee Avenue. Kowloon Tong Hong Kong, SAR China; E-mail: xiaodong.yue@cityu.edu.hk

Citation: Yue XD, Cheung CKJ, Hiranandani NA, Feng J (2018) Dispositional Predispositions of Depression, Life Satisfaction, and Life Meaning among Chinese College Students. Int J Psychol Behav Anal 4: 142. doi: https://doi. org/10.15344/2455-3867/2018/142

Copyright: @ 2018 Yue et al. This is an open-access article distributed under the terms of the Creative Commons Attribution License, which permits unrestricted use, distribution, and reproduction in any medium, provided the original author and source are credited. 
Citation: Yue XD, Cheung CKJ, Hiranandani NA, Feng J (2018) Dispositional Predispositions of Depression, Life Satisfaction, and Life Meaning among Chinese College Students. Int J Psychol Behav Anal 4: 142. doi: https://doi.org/10.15344/2455-3867/2018/142

Page 2 of 8

Depression (or non-depression), measured as experience during the recent week, is a logical precursor to life satisfaction and life meaning indicated currently. The effect is explicable with reference to deprivation theory $[34,35]$. Accordingly, depression represents deprivation that erodes mental resources or vigor, and this erosion undermines capability to maintain life satisfaction and pursue life meaning. Research has found the negative effect of depression on life satisfaction [36,37]. Similarly, research has found a negative relationship between depression and life meaning $[25,38]$.

Life satisfaction is another indicator of hedonist well-being that focuses on the cognitive aspect [39-41]. The cognitive operation involves an implicit comparison of perception with expectation such that the surplus gives satisfaction [42]. Life satisfaction can be a composite of satisfactions with various life domains, such as study and extracurricular activity [43]. It is an important protective factor against behavioral problems [44]. As such, life satisfaction is of concern in Chinese as well as other societies $[45,46]$.

Life meaning refers to the grasp of meaning in life, as regarded as necessary for existence to secure existentialist well-being $[2,47,48]$. Associated with the grasp are the person's awareness, engagement, fulfillment, self-determination, and even isolation regarding life [49]. They are necessary for existence because life is short and uncertain. The grasp is to establish purposes, goals, values, directions, and philosophies in life [50]. Life meaning, apart from its intrinsic value for the individual, contributes to volunteering and therefore others' well-being [51].

Thus conceived, this study aims to investigate relationships among personality traits, non-depression, life satisfaction, and life meaning in the college student. Specifically, neuroticism will have negative effect on non-depression, life satisfaction and life meaning. While extraversion, conscientiousness and openness will have positive effects on non-depression, life satisfaction and life meaning.

\section{Method}

\section{Participants}

The study employed a survey of 6,230 Chinese college students to collect data for analysis. These students attended each of the 52 colleges located in different places of Mainland China, Taiwan, Hong Kong, and Macau. To avoid domination by any one college, the analysis proceeded with a weighted sample such that all the colleges had equal proportions of weighted cases, and therefore were equally important.

The weighted sample showed that the students had an average age of 20.7 years (Table 1). Among them, 56.7\% were females and $43.4 \%$ were males. $41.6 \%$ were Year 1 students, $33.1 \%$ were Year 2 students, $15.9 \%$ were Year 3 students, $9.2 \%$ were students of higher grades, $50.3 \%$ were only children, $92.3 \%$ were in Mainland China, $19.2 \%$ attended Band 1 colleges, $40.4 \%$ attended Band 2 colleges, and $40.4 \%$ attended Band 3 colleges.

\section{Measures}

A combination of scales measured the student's personality traits, depression, life satisfaction, life meaning, and family income. Personality traits consisted of neuroticism, extraversion, conscientiousness, and openness. Each of them combined two items,

\begin{tabular}{|l|l|l|l|l|}
\hline & Scoring & M & SD & \\
\hline Extraversion & $0-100$ & 53.2 & 22.2 & extro \\
\hline Conscientiousness & $0-100$ & 63.6 & 20.2 & consci \\
\hline Neuroticism & $0-100$ & 46.2 & 19.2 & neuro \\
\hline Openness & $0-100$ & 63.7 & 18.6 & open \\
\hline Depression & $0-100$ & 32.8 & 12.9 & depress \\
\hline Life satisfaction & $0-100$ & 59.9 & 17.2 & satis \\
\hline Life meaning & $0-100$ & 61.0 & 16.9 & meaning \\
\hline Acquiescence & $0-100$ & 54.8 & 6.1 & acq \\
\hline Female & 0,100 & 56.7 & 49.5 & female \\
\hline Age & years & 20.7 & 2.0 & age \\
\hline Years of study & years & 1.9 & 1.0 & yr \\
\hline Family income & $0-100$ & 33.9 & 18.5 & f.inc \\
\hline Band 1 college & 0,100 & 19.2 & 39.4 & band1 \\
\hline Band 2 college & 0,100 & 40.4 & 49.1 & band2 \\
\hline Band 3 college & 0,100 & 40.4 & 49.1 & band3 \\
\hline Only child & 0,100 & 50.3 & 50.0 & only \\
\hline Mainland China & 0,100 & 92.3 & 26.6 & main \\
\hline
\end{tabular}

Table 1: Means and standard deviations $(\mathrm{N}=6,230)$

Note. "0, 100" had a score of 0 for "no" and 100 for "yes."

including one negatively phrased item that required reverse scoring [12]. All the items referred to traits all along the student's life. Items for neuroticism were "anxious, easily upset" and "calm, emotionally stable" (Table 2). Those for extraversion were "extraverted, enthusiastic" and "reserved, quiet". Conscientiousness combined the items of "dependable, self-disciplined" and "disorganized, careless." Openness combined the items of "open to new experiences, complex" and "conventional, uncreative." Confirmatory factor analysis showed that composite reliability was $.421, .413, .375$, and .353 for neuroticism, extraversion, conscientiousness, and openness respectively. The low reliability was not a problem, because structural equation modeling identified trait factors that were free of measurement error for analysis [52]. Specifically, structural equation modeling adjusted for unreliability in testing for statistical significance.

Depression combined nine items, such as "feeling down-hearted and blue" and "getting tired for no reason" (Table 2), during the recent week [26]. Confirmatory factor analysis showed that composite reliability was .762. Notably, non-depression referred to the reverse of depression to signify well-being.

Life satisfaction combined eight items, such as "study satisfaction" and "teacher satisfaction" at the current time (Table 2). Confirmatory factor analysis showed that composite reliability was .816 .

Life meaning combined six items, such as "feeling like I am living fully" and "having clear goals and aims in life" at the current time [50] (Table 2). Confirmatory factor analysis showed that composite reliability was .760 .

Acquiescence referred to the average of all unreversed rating items involved to represent a method artifact factor for controlling in structural equation modeling [53]. That is, the presence of the method factor enabled the identification of the trait factors of personality traits, depression, life satisfaction, and life meaning, which were independent of the method factor. 
Citation: Yue XD, Cheung CKJ, Hiranandani NA, Feng J (2018) Dispositional Predispositions of Depression, Life Satisfaction, and Life Meaning among Chinese College Students. Int J Psychol Behav Anal 4: 142. doi: https://doi.org/10.15344/2455-3867/2018/142

Page 3 of 8

\begin{tabular}{|c|c|c|c|}
\hline Factor/indicator & Trait & Method & \\
\hline \multicolumn{4}{|l|}{ Neuroticism } \\
\hline Anxious, easily upset & .486 & .176 & A01_04 \\
\hline (not) Calm, emotionally stable & .517 & -.284 & A01R09 \\
\hline \multicolumn{4}{|l|}{ Extraversion } \\
\hline Extraverted, enthusiastic & .465 & .477 & A01_01 \\
\hline (not) Reserved, quiet & .495 & -.028 & A01R06 \\
\hline \multicolumn{4}{|l|}{ Conscientiousness } \\
\hline Dependable, self-disciplined & .474 & .436 & A01_03 \\
\hline (not) Disorganized, careless & .439 & -.070 & A01R08 \\
\hline \multicolumn{4}{|l|}{ Openness } \\
\hline Open to new experiences, complex & .451 & .378 & A01_05 \\
\hline (not) Conventional, uncreative & .441 & .018 & A01R10 \\
\hline \multicolumn{4}{|l|}{ Non-depression } \\
\hline I feel down-hearted and blue & -.491 & -.186 & A09_01 \\
\hline I have crying spells or feel like it & -.487 & -.012 & A09_03 \\
\hline My heart beats faster than usual & -.570 & .160 & A09_09 \\
\hline I get tired for no reason & -.590 & -.062 & A09_10 \\
\hline I am restless and can't keep still & -.617 & .098 & A09_13 \\
\hline I am more irritable than usual & -.589 & .107 & A09_15 \\
\hline $\begin{array}{l}\text { I feel that others would be better off if } \\
\text { I were dead }\end{array}$ & -.470 & .175 & A09_19 \\
\hline I feel (not) hopeful about the future & -.323 & -.347 & A09R14 \\
\hline My life is (not) pretty full & -.338 & -.454 & A09R18 \\
\hline \multicolumn{4}{|l|}{ Life satisfaction } \\
\hline Overall life satisfaction & .473 & .477 & A12_01 \\
\hline Study satisfaction & .500 & .467 & A12_02 \\
\hline School satisfaction & .559 & .326 & A12_03 \\
\hline Major field satisfaction & .534 & .453 & A12_04 \\
\hline Teacher satisfaction & .652 & .333 & A12_05 \\
\hline Classmate satisfaction & .521 & .358 & A12_06 \\
\hline Dormitory satisfaction & .740 & .262 & A12_07 \\
\hline Extracurricular activity satisfaction & .401 & .368 & A12_08 \\
\hline \multicolumn{4}{|l|}{ Life meaning } \\
\hline $\begin{array}{l}\text { Having a system of values and beliefs } \\
\text { that guide daily activities }\end{array}$ & .442 & .419 & A15_01 \\
\hline $\begin{array}{l}\text { Having a philosophy of life that helps } \\
\text { understand the self }\end{array}$ & .414 & .382 & A15_02 \\
\hline Feeling like I am living fully & .467 & .550 & A15_03 \\
\hline $\begin{array}{l}\text { Feeling to have found a really } \\
\text { significant meaning in life }\end{array}$ & .558 & .480 & A15_04 \\
\hline Having clear goals and aims in life & .622 & .501 & A15_05 \\
\hline $\begin{array}{l}\text { Having a sense of direction and } \\
\text { purpose in life }\end{array}$ & .575 & .531 & A15_06 \\
\hline
\end{tabular}

Table 2: Standardized factor loadings, estimated for Model 2.

The study solicited support from the teachers of 52 colleges located in various places in Mainland China, Taiwan, Hong Kong, and Macau to engage their students in the survey. These colleges covered various kinds, including some devoted to certain specialisms, and the students pertained to various major fields of study. The students participated in the study voluntarily and completed the survey through selfadministration.

\section{Results}

Structural equation modeling, which incorporated the confirmatory factor analysis part, showed that all models attained a good fit (Table 3 ). The fit was essential to warrant detailed estimates derived for the models [54]. Notably, Model 1 and Model 2 displayed identical fit results, as they were perfect alternatives to each other. In other words, treating the three well-being factors as correlates was equally plausible with treating non-depression as a predictor of both life satisfaction and life meaning. Moreover, Model 2 fitted as well as other models, as the disadvantage (e.g., a decrease of .002 in CFI) of Model 2 was negligible [55]. In other words, constraining effects of each personality trait on the three well-being factors to be equivalent did not substantially weaken the fit. As such, Model 2 could be a comparable alternative to other models.

\begin{tabular}{|l|l|l|l|l|l|l|}
\hline Model & L2 & df & SRMR & RMSEA & CFI & \\
\hline 1. & Free & 1198 & 508 & .045 & .017 & .908 \\
\hline 2. & $\begin{array}{l}\text { Equality } \\
\text { personality effects }\end{array}$ & 1217 & 516 & .047 & .017 & .906 \\
\hline 3. & $\begin{array}{l}\text { Non-depression as } \\
\text { a mediator }\end{array}$ & 1198 & 508 & .045 & .017 & .908 \\
\hline
\end{tabular}

Table 3: Goodness of fit.

In each of the models, the confirmatory factor analysis part identified traits factors in the presence of the method factor (Table 2). The identification was evident in the substantial loadings of items on their respective factors. Notably, the non-depression factors involved negative loadings of depression items. Meanwhile, some loadings on the method factor were substantial $(>.4)$, thus indicating the need for specifying the method factor in order to distill the trait factors. For instance, some parts of life satisfaction and life meaning were due to the method factor of acquiescence, and removing these parts was necessary to unfold the trait factors of life satisfaction and life meaning.

Among the 21 inter-factor correlations after controlling for background characteristics, four were strong $(r>.4$, Table 4$)$, eight were moderate $(r=.25-.40)$, seven were weak $(r=.10-.25)$, and two were negligible $(r<.10)$, and 13 were statistically significant $(\mathrm{p}<.05)$. The correlations ranged from .058 to .492 in absolute value, showing that the factors were clearly not redundant to each other. Notably, correlations between non-depression and life satisfaction and life meaning were moderate $(r=.365 \& .372)$, and the correlation between life satisfaction and life meaning was weak $(r=.238)$.

The structural relation analysis of structural equation modeling showed that neuroticism exerted significant negative effects on the three well-being factors of non-depression, life satisfaction, and life meaning, based on Model 2 (Table 5). In the same model, extraversion, conscientiousness, and openness displayed significant effects on the three well-being factors. These findings supported Hypotheses 1, 2, 3 , and 4. Based on Model 1, the effects of each personality trait on the three well-being factors could vary, and some of the effects were insignificant. However, the general pattern was in support of the four hypotheses. This general pattern made Model 2 preferable because of its parsimony and comparable fit.

Findings for Model 3 showed a very similar picture with that of Model 1, even though Model 3 specified non-depression as a predictor of both life satisfaction and life meaning. The similarity importantly 
Citation: Yue XD, Cheung CKJ, Hiranandani NA, Feng J (2018) Dispositional Predispositions of Depression, Life Satisfaction, and Life Meaning among Chinese College Students. Int J Psychol Behav Anal 4: 142. doi: https://doi.org/10.15344/2455-3867/2018/142

Page 4 of 8

\begin{tabular}{|c|c|c|c|c|c|c|}
\hline Correlate & $\mathrm{N}$ & $\mathrm{E}$ & $\mathrm{C}$ & $\mathrm{O}$ & $\mathrm{D}$ & $S$ \\
\hline Neuroticism $(\mathrm{N})$ & 1.000 & & & & & \\
\hline Extraversion (E) & $.316^{*}$ & 1.000 & & & & \\
\hline Conscientiousness (C) & $.446^{\star * *}$ & -.121 & 1.000 & & & \\
\hline Openness $(\mathrm{O})$ & -.212 & .144 & .091 & 1.000 & & \\
\hline Non-depression (D) & $-.377^{\star * *}$ & $.156^{*}$ & $.459^{* * *}$ & $.492^{\star * *}$ & 1.000 & \\
\hline Life satisfaction (S) & -.058 & .215 & $.273^{\star *}$ & .385 & $.365^{\star}$ & 1.000 \\
\hline Life meaning (M) & $-.257^{\star * *}$ & .113 & $.456^{\star * *}$ & $.297^{\star * *}$ & $.372^{* * *}$ & $.238^{* * *}$ \\
\hline
\end{tabular}

Table 4: Inter-factor correlations.

Note. They were partial correlations, after controlling for years of study, family income, only-child status, college banding, and location.

${ }^{\star} p<.05 .{ }^{* *} p<.01 .{ }^{* *} p<.001$.

\begin{tabular}{|c|c|c|c|c|c|c|}
\hline \multirow[b]{2}{*}{ Predictor } & \multicolumn{3}{|c|}{ Model 1} & \multicolumn{3}{|c|}{ Model 2} \\
\hline & Non-depression & Life satisfaction & Life meaning & Non-depression & Life satisfaction & Life meaning \\
\hline Neuroticism (N) & $-.385^{\star \star \star}$ & -.082 & $-.264^{\star \star \star}$ & $-.206^{\star \star *}$ & $-.215^{\star \star \star}$ & $-.233^{\star \star \star}$ \\
\hline Extraversion (E) & $.186^{\star *}$ & .225 & $.134^{*}$ & $.177^{\star *}$ & $.184^{* *}$ & $.200^{* *}$ \\
\hline Conscientiousness (C) & $.503^{\star * *}$ & $.301^{\star * *}$ & $.521^{\star * *}$ & $.416^{* * *}$ & $.433^{* * *}$ & $.469^{* * *}$ \\
\hline Openness (O) & $.475^{\star * *}$ & .374 & $.290^{\star *}$ & $.350^{* * *}$ & $.365^{\star * *}$ & $.395^{* * *}$ \\
\hline Female & $.200^{*}$ & .066 & .099 & $.156^{*}$ & .103 & .105 \\
\hline Age & -.085 & -.076 & -.053 & -.064 & $-.087^{\star}$ & -.060 \\
\hline Years of study & .050 & .085 & .141 & .056 & .047 & .176 \\
\hline Family income & .005 & .038 & .027 & -.031 & .068 & .012 \\
\hline Only child & .032 & .003 & .066 & .048 & .012 & .057 \\
\hline Band 1 college & .092 & $.214^{\star * *}$ & $.168^{\star *}$ & .054 & $.253^{\star * *}$ & $.151^{*}$ \\
\hline Band 2 college & -.020 & $.145^{\star}$ & .089 & -.044 & $.183^{*}$ & .063 \\
\hline Mainland & -.052 & .023 & -.082 & -.030 & -.006 & -.081 \\
\hline$R^{2}$ & .619 & .293 & .428 & .357 & .388 & .455 \\
\hline
\end{tabular}

Table 5: Standardized effects on well-being.

Note: Male gender, non-only-child status, Band 3 college, and non-Mainland location were reference categories.

${ }^{\star} p<.05 .{ }^{* *} p<.01 .{ }^{* * *} p<.001$.

\begin{tabular}{|c|c|c|c|c|c|c|c|c|}
\hline Predictor & Non-depression & Life satisfaction & Life meaning & $\mathrm{N}$ & $\mathrm{E}$ & $\mathrm{C}$ & $\mathrm{O}$ & \\
\hline Neuroticism $(\mathrm{N})$ & $-.385^{\star \star \star}$ & -.039 & $-.360^{\star *}$ & - & - & - & - & NEURO \\
\hline Extraversion (E) & $.186^{\star *}$ & .205 & $.181^{\star}$ & - & - & - & - & EXTRO \\
\hline Conscientiousness (C) & $.503^{\star * *}$ & .245 & $.647^{\star *}$ & - & - & - & - & CONSCI \\
\hline Openness (O) & $.475^{\star * *}$ & .321 & $.408^{*}$ & - & - & - & - & OPEN \\
\hline Non-depression & - & .110 & -.249 & - & - & - & - & \\
\hline Female & $.200^{*}$ & .044 & .149 & .099 & $.155^{*}$ & -.132 & $-.205^{\star *}$ & FEMALE \\
\hline Age & -.085 & -.067 & -.074 & -.050 & .034 & .033 & .078 & AGE \\
\hline Years of study & .050 & .079 & .153 & -.075 & -.072 & .144 & $-.199^{\star}$ & YR \\
\hline Family income & .005 & .038 & .029 & .099 & .027 & -.100 & .023 & F_INC \\
\hline Only child & .032 & .000 & .074 & -.100 & .009 & $-.148^{\star}$ & .041 & ONLY \\
\hline Band 1 college & .092 & $.204^{\star * *}$ & $.191^{\star}$ & $.179^{*}$ & .035 & -.150 & .027 & BAND1 \\
\hline Band 2 college & -.020 & $.147^{\star *}$ & .084 & .101 & .126 & -.162 & .044 & BAND2 \\
\hline Mainland & -.052 & .028 & -.095 & -.034 & .015 & $.164^{* * *}$ & .021 & MAIN \\
\hline$R^{2}$ & .618 & .297 & .451 & .080 & .036 & .133 & .088 & \\
\hline
\end{tabular}

Table 6: Standardized effects on well-being, estimated for Model 3

Note. Male gender, non-only-child status, Band 3 college, and non-Mainland location were reference categories.

${ }^{\star} \mathrm{p}<.05 .{ }^{* *} \mathrm{p}<.01 .{ }^{* * *} \mathrm{p}<.001$. 
Citation: Yue XD, Cheung CKJ, Hiranandani NA, Feng J (2018) Dispositional Predispositions of Depression, Life Satisfaction, and Life Meaning among Chinese College Students. Int J Psychol Behav Anal 4: 142. doi: https://doi.org/10.15344/2455-3867/2018/142

Page 5 of 8

\begin{tabular}{|c|c|c|c|c|c|c|c|}
\hline & \multicolumn{3}{|c|}{ Fixed } & \multicolumn{3}{|c|}{ Random } & \\
\hline Predictor & Non-depression & Life satisfaction & Life meaning & Non-depression & Life satisfaction & Life meaning & \\
\hline Neuroticism (N) & $-.263^{* * *}$ & $-.167^{\star * *}$ & $-.198^{\star * *}$ & $.129^{* *}$ & $.127^{\star}$ & $.088^{\star}$ & ZNEURO \\
\hline Extraversion (E) & $.177^{\star * *}$ & $.214^{* * *}$ & $.231^{\star * *}$ & $.080^{*}$ & $.106^{*}$ & $.101^{\star *}$ & ZEXTRO \\
\hline Conscientiousness (C) & $.540^{* * *}$ & $.417^{\star * *}$ & $.575^{\star * *}$ & $.121^{*}$ & $.094^{\star *}$ & $.087^{\star}$ & ZCONSCI \\
\hline Openness (O) & $.379^{* * *}$ & $.471^{* * *}$ & $.438^{\star * *}$ & .048 & $.118^{*}$ & $.116^{\star *}$ & ZOPEN \\
\hline Female & $.200^{* * *}$ & $.156^{* * *}$ & $.167^{\star * *}$ & .024 & $.113^{\star}$ & .078 & ZFEMALE \\
\hline Years of study & $.080^{*}$ & $.107^{\star *}$ & $.173^{\star * *}$ & $.152^{\star}$ & $.112^{*}$ & $.133^{\star}$ & ZYR \\
\hline Family income & -.018 & .035 & .043 & $.199^{* *}$ & $.126^{* *}$ & $.126^{*}$ & ZF_INC \\
\hline Only child & $.049^{\star *}$ & $.031^{*}$ & $.090^{* * *}$ & .053 & .057 & .077 & ZONLY \\
\hline Band 1 college & $.177^{\star * *}$ & $.210^{* * *}$ & $.180^{\star * *}$ & .000 & .000 & .000 & ZBAND1 \\
\hline Band 2 college & .028 & $.101^{* *}$ & $.086^{* * *}$ & .000 & .000 & .068 & ZBAND2 \\
\hline Age & $-.170^{\star * *}$ & $-.082^{*}$ & $-.083^{*}$ & $.196^{\star *}$ & $.146^{*}$ & $.155^{\star}$ & ZAGE \\
\hline Mainland & $-.110^{\star *}$ & -.057 & $-.084^{* * *}$ & .000 & .000 & .000 & ZMAIN \\
\hline Acquiescence & .019 & -.019 & -.008 & .070 & $.078^{*}$ & .073 & ZACQ \\
\hline Mainland $\times \mathrm{N}$ & .026 & .015 & -.014 & .000 & .000 & .000 & Zmain_neuro \\
\hline Mainland $\times \mathrm{E}$ & .002 & .007 & -.018 & .000 & .000 & .000 & Zmain_extro \\
\hline Mainland $\times \mathrm{C}$ & -.047 & .003 & .011 & .000 & .000 & .000 & Zmain_consci \\
\hline Mainland $\times \mathrm{O}$ & -.005 & .005 & -.008 & .023 & .000 & .000 & Zmain_open \\
\hline$R^{2}$ & .726 & .621 & .735 & - & - & - & \\
\hline
\end{tabular}

Table 7: Standardized fixed and random effects on well-being.

Note. Male gender, non-only-child status, Band 3 college, and non-Mainland location were reference categories.

The random effect must not be negative, and it indicated absolute variation from the fixed effect.

${ }^{\star} \mathrm{p}<.05 .{ }^{* *} \mathrm{p}<.01 .{ }^{* * *} \mathrm{p}<.001$

showed that neuroticism exerted significant effects on life meaning ( $\beta$ $=-.360$, Table 6$)$, and extraversion $(\beta=.181)$, conscientiousness $(\beta=$ $.647)$, and openness $(\beta=.408)$ exerted significant positive effects on life meaning, even after controlling for non-depression. Meanwhile, non-depression did not manifest a significant effect on either life satisfaction $(\beta=.110)$ or life meaning $(\beta=-.249)$. This result did not support Hypothesis 5. What is more, the correlation between life satisfaction and life meaning was minimal $(r=.005)$, after controlling for personality traits and background characteristics.

Additional analysis indicated no significant locational variation in the effects of personality traits on the three well-being factors ( Table 7). That is, the interactions involving location and personality traits did not introduce significant effects on the well-being factors. The effects were minimal (maximum $\beta=.047$ in absolute value), showing that the effects of personality traits were comparable between Mainland China and the non-Mainland.

The random effects of personality traits on the three well-being factors across colleges were mostly significant, albeit the effects were week (maximum $\beta=.129$ in absolute value, see Table 7 ). In other words, most of the effects varied significantly among colleges. For instance, the standardized effect of neuroticism on non-depression could vary from -.134 to -.392 in different colleges. Nevertheless, none of the random effects of personality traits was stronger than was the corresponding fixed effects. This indicated that the random variation was not strong enough to reverse the fixed effects. Consequently, the four hypotheses about the effects of personality traits on the wellbeing factors remained to find support.
The analyses also found some consistently significant effects of background characteristics on the well-being factors and personality traits. These effects were the positive effects of female gender on nondepression; and the positive effects of Band 1 and Band 2 colleges on life satisfaction and life meaning. That is, the female students were lower in depression and the Band 3 college students were lower in life satisfaction and life meaning. In addition, significant findings about personality traits showed that the female students were higher in extra version $(\beta=.155$, see Table 6$)$ and lower in openness $(\beta=-.205)$ than male students. The more senior student was lower in openness $(\beta=-.199)$. The only child was lower in conscientiousness $(\beta=-.148)$ than one with siblings. The Band 1 college students were higher in extraversion $(\beta=.179)$ than were Band 3 students. The students in Mainland China were higher in conscientiousness $(\beta=.164)$ than were the Chinese student outside Mainland China. All the significant background effects, nevertheless, were weak.

\section{Discussion}

Results proffered robust support for the four hypotheses concerning the effects of personality traits on the three well-being factors of nondepression, life satisfaction, and life meaning in the Chinese college student. Specifically, neuroticism maintained a negative effect on the well-being factors, and extraversion, conscientious, and openness evolved positive effects of the factors. These effects were robust in that locational variation in the effects was insignificant and random variation across colleges was not strong enough to nullify the effects. More importantly, the effects of each personality trait could be constrained to be equal in a parsimonious model without impairing the model fit. That is, each personality trait tends to predispose nondepression, life satisfaction, and life meaning similarly. 
Despite the similar pattern of personality effects, the three well-being factors demonstrated some differences in relation to personality traits. These differences were transparent when personality traits displayed effects on life meaning even after controlling for non-depression. Moreover, non-depression did not show effects on life satisfaction and life meaning, in the presence of the effects of personality traits. That is, personality traits rather than depression were the predictors of life meaning. Hence, the three well-being factors, albeit inter-correlated, turned out to be independent after controlling for personality traits. In other words, observable relationships among depression, life satisfaction, and life meaning are attributable to the common influences of personality traits.

Dissimilarity among the three well-being factors is evident in the distinction between hedonist and existentialist views. Notably, life meaning originates from the existentialist view, whereas life satisfaction and non-depression index the hedonist view. The existentialist emphasizes the person's freedom, choice, and taking responsibility for deriving meaning for the turbulent life [3] Moreover, the maintenance of life meaning stands as a vital life goal and project [56]. As such, the maintenance of life meaning would particularly benefit from the person's conscientiousness exhibited as striving and perseverance for the maintenance. Meanwhile, the maintenance is effortful and can even be painful, thus occasionally meeting with frustration and depression [57,58]. Depression is likely to spur as well as impede the maintenance $[56,59]$. Because of its reliance on personality traits such as conscientiousness, life meaning would be independent of non-depression.

The female students were higher than were the male students in non-depression and extraversion, and were lower in openness. That is, that the females were lower in depression were surprising, given some research and theory about hormonal influence and social status $[60,28]$. Nevertheless, some studies have found that the females were lower in depression [61,62]. In particular, the female Chinese students may enjoy relatively favorable social life [63]. With respect to the theory about social status, the females may therefore experience lower depression. Similarly, the female youth appears to be higher in social maturity and activity than does the male youth $[64,65]$. The female's greater social engagement just reflects her higher extraversion. Moreover, females are more religious and less realistically oriented than is the male $[65,66]$. These characteristics just reflect lower openness in the females [65].

Another surprising finding is that the students attending a Band 1 college manifested higher life satisfaction, life meaning, and neuroticism than did the students attending a Band 3 college. The former contradicts the expectation that the selectivity of college weakens the student's life satisfaction [67]. According to set-point theory, some predispositions would enable the youth's entrance into a higher-quality college and sustain higher life satisfaction and life meaning. This is possible through the youth's generalized ability $[68,69]$. Meanwhile, a selective or competitive context would engender neuroticism [70].

Conscientiousness was lower in the only child and the Chinese student outside Mainland China in than other students. The only child tends to be less competitive [71,72]. Meanwhile, competitiveness or achievement orientation is a basis for conscientiousness [73]. Therefore, the only child is like to be lower in conscientiousness than is others. By the same vein, achievement and competition orientations are high in Mainland China [74,75]. The orientation may sustain conscientiousness there.
Finally, for the maintenance of the well-being of Chinese college students, sustaining their conscientiousness, openness, and extraversion and taking care of their neuroticism would be effective. Meanwhile, Band 3 college students require more support for them to bolster their well-being. Band 1 students, by contrast, require more support to tackle their higher neuroticism. More particularly, prevention of depression is a concern more for male students than for female students. The male students also need a higher concern than female students about their lower extraversion. In contrast, the female students require a higher concern about their lower openness. The only child is in need of greater concern about his or her lower conscientiousness.

\section{Limitations and Future Research}

The study is limited in its focus on students in selected Chinese colleges and one-time measurement. As such, the generalizability and validity of its findings decidedly require future research to verify and substantiate. Although the study finds no difference in personality effects between Mainland China and Chinese societies outside Mainland China, the study find substantial random variation among colleges. As such, sampling of colleges may make a difference in findings about the effects, even though the difference may not be dramatic. Moreover, because variation among colleges also reflects that among cities, student population, and other background characteristics. This means that future research needs to take care of sampling of colleges, cities, and other characteristics. Moreover, future research needs to enhance the validity of measurement. Notably, the one-time measurement cannot guarantee the durability of and causal primacy of personality traits. It also cannot ascertain changes in the well-being factors and their dependence on personality traits. Preventing these limitations requires future research to measure personality traits and well-being repeatedly to verify that prior personality traits produce changes from prior well-being to later well-being. Preferably, future research can collect data not just from Chinese societies, but also other places, in order to make research findings generalizable for the world.

\section{Competing Interests}

The authors declare that they have no competing interests.

\section{References}

1. Son J, Wilson J (2012) Volunteer work and hedonic, eudemonic, and social well-being. Sociological Forum 27: 658-681.

2. Thin N (2012) Social happiness: Theory into policy and practice. Bristol, UK: Polity

3. Osafo Hounkpatin H, Wood AM, Boyce CJ, Dunn G (2014). An existentialhumanistic view of personality change: co-occurring change with psychological well-being in a 10 year cohort study. Social Indicators Research 12: 455-470

4. Shin DC, Inoguchi T (2009) Avowed happiness in Confucian Asia: Ascertaining its distribution, patterns and sources. Social Indicators Research 92: 405-427.

5. O'Connor K, Chamberlain K (1996) Dimensions of life meaning: A qualitative investigation at mid-life. British Journal of Psychology 87: 461-427.

6. Phillips D (2006) Quality of life: Concept, policy and practice. London: Routledge.

7. Fagley NS (2012) Appreciation uniquely predicts life satisfaction above demographics, the big 5 personality factors, and gratitude. Personality \& Individual Differences 53: 59-63. 
Citation: Yue XD, Cheung CKJ, Hiranandani NA, Feng J (2018) Dispositional Predispositions of Depression, Life Satisfaction, and Life Meaning among Chinese College Students. Int J Psychol Behav Anal 4: 142. doi: https://doi.org/10.15344/2455-3867/2018/142

8. Mascaro N, Rosen DH (2005) Existential meaning's role in the enhancement of hope and prevention of depressive symptoms. Journal of Personality 73 : 985-1014.

9. Steger MF, Frazier P, Oishi S, Kaler M (2006) The Meaning in Life Questionnaire: Assessing the presence of and search for meaning in life. Journal of Counseling Psychology 53: 80-93.

10. Arterberry BJ, Martens MP, Cadigan JM, Rohrer D (2014) Application of generalizability theory to the Big Five Inventory. Personality \& Individual Differences 69: 98-103.

11. Anusic I, Lucas RE, Donnellan MB (2012) Dependability of personality: Life satisfaction, and affect in short-term longitudinal data. Journal of Personality 80: 33-58.

12. Gosling SD, Rentfrow PJ, Swann WB (2003) A very brief measure of the Big-Five personality domains. Journal of Research in Personality 37: 504 528

13. Epstein S (2010) The big five model: Grandiose ideas about surface traits as the foundation of a general theory of personality. Psychological Inquiry 21: 34-39.

14. Feist GJ (2010) The foundation of personality in creativity: The nature and nurture of Creative personality. In J. C. Kaufman \& R. J. Sternberg (Eds.) The Cambridge handbook of creativity. New York: Cambridge University Press.

15. Trapman S, Hell B, Hirn JOW, Schuler H (2007) Meta-analysis of the Relationship between the big five and academic success at university. Journal of Psychology 215: 132-151.

16. Beckerman W (2011) Economics as applied ethics: Value judgements in welfare economics. Houndmills UK: Palgrave.

17. Headey B (2008) The set-point theory of well-being: Negative, results and consequent revisions. Social Indicators Research 83: 389-403.

18. Diener, E, Lucas RE (1999) Personality and Subjective Well-being. In D. Kahneman, E. Diener \& N. Schwarz (Eds.), Well-being: The foundations of hedonic psychology. New York: Russell Sage.

19. Ryan RM, Deci EL (2001) On happiness and human potentials: A review of research on hedonic and eudaimonic well-being. Annual Review of Psychology 52: 151-166.

20. Moller V (2001) Happiness trends under democracy: Where will the New South African set-level come to rest? Journal of Happiness Studies 2: 3353.

21. Vanhalst J, Klimstra TA, Luyckx K, Scholte RH, Engels RC, et al. (2012) The interplay of loneliness and depressive symptoms across adolescence: Exploring the role of personality traits. Journal of Youth \& Adolescence 41 776-787.

22. Mak AS, Blewitt K, Heaven PCL (2004) Gender and personality influences in adolescent threat and challenge appraisals and depressive symptoms. Personality \& Individual Differences, 36; 1483-1490.

23. Zhang JW, Howell RT (2011) Do time perspectives predict unique variance in life satisfaction beyond personality traits? Personality \& Individua Differences 50: 1261-1266.

24. Hofer J, Busch H, Kiessling F (2008) Individual pathways to life satisfaction The significance of traits and motives. Journal of Happiness 9: 509-520.

25. Steger MF, Kashdan TB, Sullivan BA, Lorentz D (2008) Understanding the search for meaning in life: Personality, cognitive style, and the dynamic between seeking and experiencing meaning. Journal of Personality 76 199-228.

26. Zung WW (1965) A self-rating depression scale. Archives of Genera Psychiatry 12: 63-70.

27. Cytryr L, McKnew DHJr (1996) Growing up sad: Childhood depression and its treatment. New York: Norton.

28. Qouta S, Punamäki RL, Montgomery E, El Sarraj E (2007) Predictors of psychological distress and positive resources among Palestinian adolescents: Trauma, child, and mothering characteristics. Child Abuse \& Neglect 31: 699-717.

29. Wang YC, Supple AJ (2010) Parent behaviors and adolescent psychosocia adjustment in China: An indigenous perspective. Marriage \& Family Review 46: 480-497.

30. Yi CC, Wu Cl, Chang YH, Chang MY (2009) The psychological wellbeing of Taiwanese youth school versus family context from early to late adolescence. International Sociology 24: 397-429.
31. Mortimer JT, Harley C, Staff J (2002) The quality of work and youth mental health. Work \& Occupations 29: 166-197.

32. Roeser RW, Strobel KR, Guihuis G (2002) Studying early adolescents academic motivation, social-emotional functioning, and engagement in learning variable- and person-centered approaches. Anxiety, Stress \& Coping 15: 345-368.

33. Nordenmark M (2004) Multiple social roles and well-being: A longitudinal test of the role stress theory and the role expansion theory. Acta Sociologia, 47: 115-126.

34. Brockmann H, Delhey J, Welzel C, Yuan H (2009) The China puzzle: Falling happiness in a rising economy. Journal of Happiness Studies 10: 387-405.

35. Tyler TR, Boerkmann RJ, Smith HJ, Huo YJ (1997) Social justice in a diverse society. Boulder, CO: Westview.

36. Groot W, Van Den Brink HM (2003) Sympathy and the value of health. Social Indicators Research 61: 97-120.

37. Lewinsohn PM, Redner JE, Selley JR (1991) The relationship between life satisfaction and psychosocial variables: new perspectives. In F. Strack, M. Argyle \& N. Schwarz (Eds.), Subjective well-being: An interdisciplinary perspective. Oxford: Pergamon Press.

38. Tomich PL, Helgeson VS (2002) Five Years Later: A Cross-sectional Comparison of Breast Cancer Survivors with Healthy Women. PsychoOncology 11: 154-169.

39. Heidemeier H, Staudinger UM (2012) Self-evaluation process in life satisfaction: Uncovering measurement non-equivalence and age-related differences. Social Indicators Research 105: 39-61.

40. Lai JC, Yue X (2000) Measuring optimism in Hong Kong and mainland Chinese with the revised Life Orientation Test. Personality and Individual Differences 28: 781-796.

41. Vermunt R, Spaans E, Zorge F (1989) Satisfaction, happiness and wellbeing of Dutch students. Social Indicators Research 21: 1-33.

42. Schyns $P(2000)$ The relationship between income changes in income and life satisfaction in West Germany and the Russian Federation: Relative, absolute, or a combination of both? In E. Diener \& D. R. Rahtz (Eds.), Advances in quality of life theory and research. Dordrecht, Netherlands: Kluwer Academic.

43. Gilligan TD, Huebner S (2007) Initial development and validation of the multidimensional students' Life Satisfaction Scale: Adolescent version. Applied Research in Quality of Life 2: 1-16.

44. Sun RCF, Shek DTL (2010) Life satisfaction, positive youth development, and problem behavior among Chinese adolescents in Hong Kong. Social Indicators Research 95: 455-474.

45. Kwan YK (2010) Life satisfaction and self-assessed health among adolescents in Hong Kong. Journal of Happiness Studies 11: 383-393.

46. Shao Y, Yao X, Li Y, Huang Z (2013) Personality and life satisfaction in China: The birth order effect under the influence of national policy. Personality \& Individual Differences 54: 536-541.

47. Hodge $\mathrm{J}$ (1990) The quality of life: A contrast between utilitarian and existentialist approaches. In S. Baldwin, C. Godfrey \& C. Propper (Eds.), Quality of life: Perspectives and policies. London: Routledge.

48. Yue XD, Hao X, Goldman GL (2010) Humor styles, dispositional optimism, and mental health among undergraduates in Hong Kong and China Journal of Psychology in Chinese Societies.

49. Yalom ID (1980) Existential psychotherapy. New York: Basic Books.

50. Krause $N$ (2007) Evaluating the stress-buffering function of meaning in life among older people. Journal of Aging \& Health 19: 792-812.

51. Law BMF, Shek DTL (2011) Validation of the Beliefs against Volunteering Scale among Chinese Adolescents in Hong Kong. Social Indicators Research 100: 287-298

52. Kline RB (2005) Principles and practice of structural equation modeling (2nd ed.). New York: Guilford.

53. Ferrando PJ, Lorenzo-Seva U (2010) Acquiescence as a source of bias and model and personal misfit: A theoretical and empirical analysis. British Journal of Mathematical \& Statistical Psychology 63: 427-448.

54. Marsh HW, Hau KT, Wen Z (2004) In search of golden rules: Comment on hypothesis-testing approaches to setting cutoff values for fit indexes and dangers in overgeneralizing Hu and Bentler's (1999) findings. Structural Equation Modeling 11: 320-341. 
Citation: Yue XD, Cheung CKJ, Hiranandani NA, Feng J (2018) Dispositional Predispositions of Depression, Life Satisfaction, and Life Meaning among Chinese College Students. Int J Psychol Behav Anal 4: 142. doi: https://doi.org/10.15344/2455-3867/2018/142

55. Cheung GW, Rensvold RB (2002) Evaluating goodness-of-fit indexes for testing measurement invariance. Structural Equation Modeling 9: 233-255.

56. Trent J, Lavelock C, King LA (2013) Processing fluency, positive affect, and judgments of meaning in life. Journal of Positive Psychology 8: 135-139.

57. Mancini AD, Prati G, Bonanno GA (2011) Do shattered worldviews lead to complicated grief? Prospective and longitudinal analyses. Journal of Social \& Clinical Psychology 30: 184-215.

58. Schnell T (2009) The Sources of Meaning and Meaning in Life Questionnaire (SoMe): Relations to demographics and well-being. Journal of Positive Psychology 4: 483-499.

59. Baumeister RF, Vohs KD, Aaker JL, Garbinsky EN (2013) Some key differences between a happy life and a meaningful life. Journal of Positive Psychology 8: 505-516.

60. Prinstein MJ (2007) Moderators of peer contagion: A longitudinal examination of depression socialization between adolescents and their best friends. Journal of Clinical Child \& Adolescent Psychology 36: 159170

61. Dunifon R, Kowaleski-Jones $L$ (2003) The influences of participation in the national school lunch program and food insecurity on child well-being Social Service Review 77: 73-92.

62. Peltonen K, Quota S, Elsarraj E, Punamaki RL (2010) Military trauma and social development: The moderating and mediating roles of peer and sibling relations in mental health. International Journal of Behavioral Development 34: 554-563.

63. Edwards GD, Bangert AW, Shinfuku GN, Chen T, Bi Y, et al. (2005) The impact of sibling status on Chinese college students' quality of life. Social Behavior \& Personality 33: 227-242.

64. Gutman LM, Schoon I (2012) Correlates and consequences of uncertainty in career aspirations: Gender differences among adolescents in England Journal of Vocational Behavior 80: 608-618.

65. Tokar DM, Thompson M N, Plaufcan MR, Williams CM (2007) Precursors of learning experiences in social cognitive career theory. Journal of Vocational Behavior 71: 319-339.

66. Argyle M (1994) The psychology of social class. London: Routledge

67. Pascarella ET, Terenzini PT (2005) How college affects students, vol. 2: A third decade of research. San Francisco, CA: Jossey-Bass.

68. Petrides KV, Pita R, Kokkinaki F (2007) The location of trait emotional intelligence in personality factor space. British Journal of Psychology 98 : 273-289.

69. Pinquart M, Silbereisen RK, Juang LP (2004) Moderating effects of adolescents' self-efficacy beliefs on psychological responses to socia change. Journal of Adolescent Research 19: 340-359.

70. van Hemert DA, van de Viver FJR, Poortinger YH, Georgas J (2002) Structural and functional equivalence of the Eysenck Personality Questionnaire within and between-countries. Personality \& Individual Differences 33: 1229-1249.

71. Duggan AP, Le Poire Molineux BA (2013) The reciprocal influence of drug and alcohol abuse and family members' communication. In A. L. Vangelisti (Ed.), The Routledge handbook of family communication. New York: Routledge.

72. Makepeace G, Pal S (2008) Understanding the effects of siblings on child mortality: Evidence from India. Journal of Population Economy 21: 877902

73. Ackerman PL, Wolman SD (2007) Determinants and validity of selfestimates of abilities and self-concept measures. Journal of Experimenta Psychology: Applied 13: 57-78.

74. Lau M, Li W (2011) The extent of family and school social capital promoting positive subjective well-being among primary school children in Shenzhen, China. Children \& Youth Services Review 33: 1573-1582.

75. Zhang MY, Stening BW (2010) China 2.0: Transformation of an emerging superpower and the new opportunities. Singapore: Wiley. 